\title{
Association of Inflammasome Components in Background Liver with Poor Prognosis After Curatively-resected Hepatocellular Carcinoma
}

\author{
FUMINORI SONOHARA ${ }^{1,2}$, YOSHIKUNI INOKAWA ${ }^{1,2}$, MITSURO KANDA $^{1}$, \\ YOKO NISHIKAWA ${ }^{1}$, SUGURU YAMADA ${ }^{1}$, TSUTOMU FUJII ${ }^{1}$, \\ HIROYUKI SUGIMOTO ${ }^{1}$, YASUHIRO KODERA ${ }^{1}$ and SHUJI NOMOTO ${ }^{1,2}$ \\ ${ }^{1}$ Department of Gastroenterological Surgery, Nagoya University Graduate School of Medicine, Nagoya, Japan; \\ ${ }^{2}$ Department of Surgery, Aichi-Gakuin University School of Dentistry, Nagoya, Japan
}

\begin{abstract}
Background/Aim: Inflammasomes are multiprotein complexes that evoke key inflammatory cascades. The present study evaluated the influence of inflammasome component expression in non-tumorous tissue on postsurgical hepatocellular carcinoma (HCC) prognosis. Materials and Methods: The expressions of candidate genes were investigated using real-time quantitative reverse-transcription polymerase chain reaction in resected HCC cases. In order to identify potential prognostic factors, statistical analyses were performed for each gene. Results: The expression of nod-like receptor family, pyrin domain containing 3 (NLRP3), nod-like receptor family, CARD domain containing 4 (NLRC4), and absent in melanoma 2 (AIM2) was significantly higher in corresponding normal tissue $(C N)$ compared to those in HCC. High expression of NLRP3, NLRC4, and caspase 1 (CASP1) in CN was significantly correlated with worse overall survival. Furthermore, multivariate analysis revealed that NLRP3 expression in $C N$ greater than the median was an independent prognostic factor for poorer overall survival. Conclusion: High expression of NLRP3, NLRC4, and CASP1 in background non-tumorous liver is significantly correlated with poor prognosis of patients after resection of HCC.
\end{abstract}

Hepatocellular carcinoma (HCC) represents the fifth most common malignancy and the third most common cause of cancer-related death, worldwide (1). Hepatic resection is one

Correspondence to: Shuji Nomoto, Department of Surgery, AichiGakuin University School of Dentistry, 2-11, Suemori-dori, Chikusa-ku, Nagoya, 464-8651, Japan. Tel: +81 527592167, Fax: +81 527592107, e-mail: snomoto@dpc.agu.ac.jp

Key Words: Inflammasome, hepatocellular carcinoma, hepatectomy, prognosis, background liver. of the most effective treatments for non-metastatic HCC cases (2-4), However, after curative resection, $\sim 80 \%$ of patients develop intrahepatic recurrence, and $50 \%$ die within 5 years (5). Therefore, although surgical resection for early HCC can be curative, the high tendency towards recurrence is of major concern (6).

Intrahepatic HCC recurrence is categorized as intrahepatic metastasis (IM) or multicentric occurrence (MO). IM refers to HCC foci developing from tumor cells that spread into the remnant liver via the portal vein before or during hepatic resection. MO refers to postsurgical HCC foci development due to chronic active hepatitis or cirrhosis, which is due to viruses, alcohol, toxins, or other HCC-relevant risk factors (7-10). Previous studies have indicated that the clinical progression and outcome of IM and MO differ significantly (9-11). To distinguish between them, several studies have utilized genetic background analysis of recurrent and primary tumors, which also have different progression and outcome characteristics $(6,12)$. We previously investigated genotypes in recurrent HCC by detecting mutations of the mitochondrial genome (13), or examining patterns of promoter hypermethylation in several tumor-suppressor genes in HCC (14), and our findings suggested that MO was more common than IM.

Great efforts have been made to predict $\mathrm{HCC}$ prognosis by identifying risks using the resected tumor tissue alone. However, in consideration of the greater likelihood of MO in $\mathrm{HCC}$, focusing on the tumor tissue alone might be insufficient. In any case, consideration of any correlation between HCC tissue and background non-tumorous tissue is important. We previously demonstrated that alterations in gene profiles of the non-tumorous liver tissue are also associated with HCC prognosis (15).

The relationship between inflammation and neoplasms has been demonstrated empirically e.g. chronic hepatitis and HCC, Helicobacter pylori infection and gastric neoplasms, 
and inflammatory bowel diseases and colorectal cancer. Inflammation has both antitumor and tumor-promoting effects in the tumor microenvironment (16), and inflammasomes are thought to play an important role via inflammatory pathways $(17,18)$. Recently, a relationship between cancer and inflammasomes has been suggested (19), but there are few reports describing the relationships between inflammasomes and cancer prognosis, especially that of HCC.

We hypothesized that an inflammatory status in the background non-tumorous tissues surrounding $\mathrm{HCC}$ might influence patient prognosis directly because of $\mathrm{MO}$ and indirectly by affecting the malignancy of primary HCC tissue. Therefore, the present study was designed to evaluate differences in the expressions of inflammasome components in HCC and corresponding non-tumorous tissues, and to identify unique biological markers of prognosis, especially in relation to background non-tumorous tissue of HCC.

\section{Materials and Methods}

HCC cases for real-time quantitative reverse-transcription polymerase chain reaction (RT-PCR) analysis. Primary HCC tumor tissue and surrounding corresponding non-tumorous tissues $(\mathrm{CN})$ were obtained from 158 consecutive patients who underwent curative resection at Nagoya University Hospital between 1998 and 2011. Resection was defined as curative when gross tumors were removed completely; cases of incidentally found small lesions suspected to be HCC that were treated intraoperatively by radiofrequency therapy or microwave coagulation therapy were also regarded as curative cases. Patient characteristics are summarized in Table I. The median followup duration was 48.5 months (range $=0.3-193.8$ months). All tissue samples were histologically confirmed as HCC. This study was approved by the Institutional Review Board (11001022), and all patients provided written informed consent.

Control samples, termed super normal (SN) liver, were obtained from the normal tissues of 11 patients with liver-metastatic cancer who underwent liver resection at our institution. Their primary diseases were colorectal cancer in five cases, gastrointestinal stromal tumor in two, gastric cancer in one, esophageal cancer in one, cervical cancer in one, and tongue cancer in one.

RNA was extracted from the $\mathrm{HCC}, \mathrm{CN}$, and $\mathrm{SN}$ tissues after appropriate pathological confirmation that the HCC samples included cancerous tissue and $\mathrm{CN}$ and $\mathrm{SN}$ samples did not contain any cancerous regions.

RNA isolation from tissues. Surgically obtained tissue samples were immediately frozen in liquid nitrogen and stored at $-80^{\circ} \mathrm{C}$ until analysis. Total RNA was extracted from the HCC, CN, and SN samples using a Qiagen miRNeasy Mini Kit (Qiagen, Toronto, Canada). RNA quality was confirmed according to an RNA integrity number of 8 or more as measured using an Agilent 2100 Bioanalyzer (Agilent, Santa Clara, CA, USA).

Real-time quantitative reverse-transcription PCR. The absolute quantification method was used to determine the input copy number by relating the PCR signal to a standard curve. Total CDNA was developed from the RNA extracted from each tissue with M-MLV Reverse Transcriptase (Invitrogen Carlsbad, CA, USA). This total
Table I. Characteristics of patients with hepatocellular carcinoma $(n=158)$.

\begin{tabular}{lc}
\hline Characteristic & Value \\
\hline Median age (range), years & $65(37-84)$ \\
Gender, n (\%) & $132(84): 26(16)$ \\
$\quad$ Male:female & \\
Viral infection, n (\%) & $41(26): 92(58): 28(18)$ \\
HBV:HCV:non-HBV/HCV & $148(94): 9(6)$ \\
Child-Pugh classification, n (\%) & \\
A:B & $126(83): 25(16): 1(1)$ \\
Liver damage classification, n (\%) & $3.9(2.3-4.9)$ \\
A:B:C & $0.7(0.2-7.3)$ \\
Median albumin (range), g/dl & $89.7(46.9-138)$ \\
Median total bilirubin (range), mg/dl & $17(0.8-119923)$ \\
Median PT (range), $\%$ & $3.5(0.15-15)$ \\
Median AFP (range), ng/ml & \\
Median tumor size (range), cm & $124(78): 34(22)$ \\
Tumor multiplicity, n (\%) & $11.5(1.6-35.2)$ \\
$\quad$ Solitary:multiple & \\
Median ICG-R15 (range), $\%$ & $17(11): 82(52): 40(26): 17(11)$ \\
Japanese stage, n (\%) & \\
I:II:III:IV &
\end{tabular}

HBV, Hepatitis B virus; HCV, hepatitis C virus; PT, prothrombin time; AFP, alpha-fetoprotein; ICG-R15, retention rate of indocyanine green 15 min after administration.

cDNA was used as a template for next step of quantitative PCR. PCR was performed using SYBR Premix Ex Taq II (Takara Clontech, Kyoto, Japan) under the following conditions: denaturing at $95^{\circ} \mathrm{C}$ for $10 \mathrm{sec}$, and 40 cycles of denaturing at $95^{\circ} \mathrm{C}$ for $5 \mathrm{sec}$ and annealing/extension at $60^{\circ} \mathrm{C}$ for $30 \mathrm{sec}$. The SYBR Green signal was detected in real-time using StepOne Plus Real-Time PCR System (Life Technologies, Carlsbad, California, United States).

In the present study, we focused initially on the mRNA expression of 6 major inflammasome components NLRP1, NLRP3, NLRC4, AIM2, PYCARD, and CASP1. Those genes that could be evaluated using a minimal amount of sample (NLRP3, NLRC4, AIM2, and CASP1) were selected for subsequent investigation by RT-qPCR.

The PCR primers used in current study were for a 122-bp fragment of NLRP3 (Nod-like receptor family, pyrin domain containing 3) (sense, 5'-TGCGAGGCAACACTCTCGGA-3' in exon 8; antisense 5'-CCAGCAGCAGTGTGACGTGA-3' in exon 9), a 119-bp fragment of NLRC4 (Nod-like receptor family, caspase recruitment domain containing 4) (sense, 5'-GCCAGTCCCCTCACCATAGA-3' in exon 5; antisense 5'-CCCAAGCTGTCAGTCAGACC-3' in exon 6), a 163bp fragment of AIM2 (absent in melanoma 2) (sense, 5'-GCTGGT GAAACCCCGAAGAT-3' in exon 4; antisense 5'-CCTCGTTTCTA ACCCCCAGT-3' in exon 5), and a 218-bp fragment of CASP1 (caspase 1, apoptosis-related cysteine peptidase) (sense, 5'CCCTGGTGTGGTGTGGTTTA-3' in exon 6; antisense 5'CAGAGCCCATTGTGGGATGT-3' in exon 7). Glyceraldehyde-3phosphate dehydrogenase $(G A P D H)$ (sense, 5'-GAAGGTGAAG GTCGGAGTC-3'; antisense 5'-GAAGATGGTGATGGGATTTC-3'; probe 5'-[Fl]CAAGCTTCCCGTTCTCAGCC[Fl-Q]-3') expression was quantified in each sample for standardization purposes. All realtime quantitative RT-PCR assays were performed in triplicate, 
Table II. Clinicopathological findings in patients with hepatocellular carcinoma according to expression of nod-like receptor family, pyrin domaincontaining 3 (NLRP3) in corresponding non tumorous tissue $(C N)$. Chi-square or Fisher's exact test was applied as appropriate. Significant pvalues are shown in bold.

\begin{tabular}{|c|c|c|c|c|c|}
\hline \multirow[t]{2}{*}{ Clinicopathological factor } & & \multicolumn{4}{|c|}{ NLRP3 expression in CN (vs. median), $\mathrm{n}$} \\
\hline & & Lower & Higher & $p$-Value & (Missing values) \\
\hline \multirow[t]{2}{*}{ Age } & $\geq 65$ Years & 39 & 43 & 0.5242 & \\
\hline & $<65$ Years & 40 & 36 & & \\
\hline \multirow[t]{2}{*}{ Gender } & Male & 69 & 63 & 0.1980 & \\
\hline & Female & 10 & 16 & & \\
\hline \multirow[t]{2}{*}{ Virus infection } & $\mathrm{HCV}$ & 42 & 50 & 0.1969 & \\
\hline & Other & 37 & 29 & & \\
\hline \multirow[t]{2}{*}{ Albumin } & $<3.5 \mathrm{~g} / \mathrm{dl}$ & 17 & 15 & 0.7219 & \\
\hline & $\geq 3.5 \mathrm{~g} / \mathrm{dl}$ & 62 & 63 & & (1) \\
\hline \multirow[t]{2}{*}{ PT } & $<70 \%$ & 3 & 16 & 0.0013 & \\
\hline & $\geq 70 \%$ & 76 & 62 & & (1) \\
\hline \multirow[t]{2}{*}{ ICG R15 } & $\geq 15 \%$ & 15 & 14 & 0.8168 & \\
\hline & $<15 \%$ & 45 & 38 & & (46) \\
\hline \multirow{2}{*}{ Liver cirrhosis } & With & 23 & 32 & 0.0910 & \\
\hline & Without & 56 & 44 & & (3) \\
\hline \multirow[t]{2}{*}{ Child-Pugh } & B & 4 & 5 & 0.7458 & \\
\hline & A & 75 & 73 & & (1) \\
\hline \multirow[t]{2}{*}{ Liver damage } & $\mathrm{B}$ or $\mathrm{C}$ & 9 & 17 & 0.0517 & \\
\hline & A & 70 & 56 & & (6) \\
\hline \multirow[t]{2}{*}{ Tumor number } & Multiple & 19 & 15 & 0.4387 & \\
\hline & Solitary & 60 & 64 & & \\
\hline \multirow[t]{2}{*}{ Tumor size } & $\geq 2 \mathrm{~cm}$ & 65 & 62 & 0.6371 & \\
\hline & $<2 \mathrm{~cm}$ & 13 & 10 & & (8) \\
\hline \multirow[t]{2}{*}{ AFP } & $\geq 20 \mathrm{ng} / \mathrm{ml}$ & 34 & 35 & 0.8153 & \\
\hline & $<20 \mathrm{ng} / \mathrm{ml}$ & 44 & 42 & & (3) \\
\hline \multirow[t]{2}{*}{ Differentiation } & Poor & 6 & 6 & 0.9626 & \\
\hline & Well/moderate & 72 & 70 & & \\
\hline \multirow[t]{2}{*}{ Growth form } & Infiltrative & 12 & 11 & 0.9002 & \\
\hline & Expansive & 67 & 65 & & (3) \\
\hline \multirow[t]{2}{*}{ Formation of capsule } & Without & 55 & 57 & 0.7262 & \\
\hline & With & 24 & 22 & & \\
\hline \multirow[t]{2}{*}{ Infiltration to capsule } & Yes & 43 & 45 & 0.6805 & \\
\hline & No & 36 & 33 & & (1) \\
\hline \multirow[t]{2}{*}{ Septal formation } & Without & 24 & 25 & 0.7771 & \\
\hline & With & 54 & 51 & & (4) \\
\hline \multirow[t]{2}{*}{ Serosal invasion } & Yes & 20 & 14 & 0.4449 & \\
\hline & No & 57 & 54 & & (13) \\
\hline \multirow[t]{2}{*}{ Portal/hepatic vein invasion } & Yes & 20 & 14 & 0.4449 & \\
\hline & No & 57 & 54 & & (13) \\
\hline \multirow[t]{2}{*}{ Surgical margin } & Positive & 9 & 15 & 0.1690 & \\
\hline & & 65 & 58 & & $(20)$ \\
\hline \multirow[t]{2}{*}{ Japanese stage } & III/IV & 30 & 28 & 0.8351 & \\
\hline & $\mathrm{I} / \mathrm{II}$ & 49 & 49 & & (2) \\
\hline
\end{tabular}

n: Number of patients, HCV: hepatitis C virus, PT: prothrombin time, ICG R15: indocyanine green 15-min retention rate, AFP: alpha fetoprotein.

including the template-omitted negative controls. Each gene expression was determined as the value of expression/ glyceraldehyde3 -phosphate dehydrogenase $(\mathrm{GAPDH}) \times 10^{3}$ for each sample.

Statistical analyses. Continuous variables are expressed as medians (ranges) and were compared using the Mann-Whitney $U$-test.
Categorical variables were compared using the $\chi^{2}$ or Fisher's exact test, as appropriate. Recurrence-free survival (RFS) and overall survival (OS) rates which are measured from the day of the surgery were estimated using the Kaplan-Meier method and compared using the log-rank test. Univariate and multivariate Cox proportional hazards models were used to determine the 

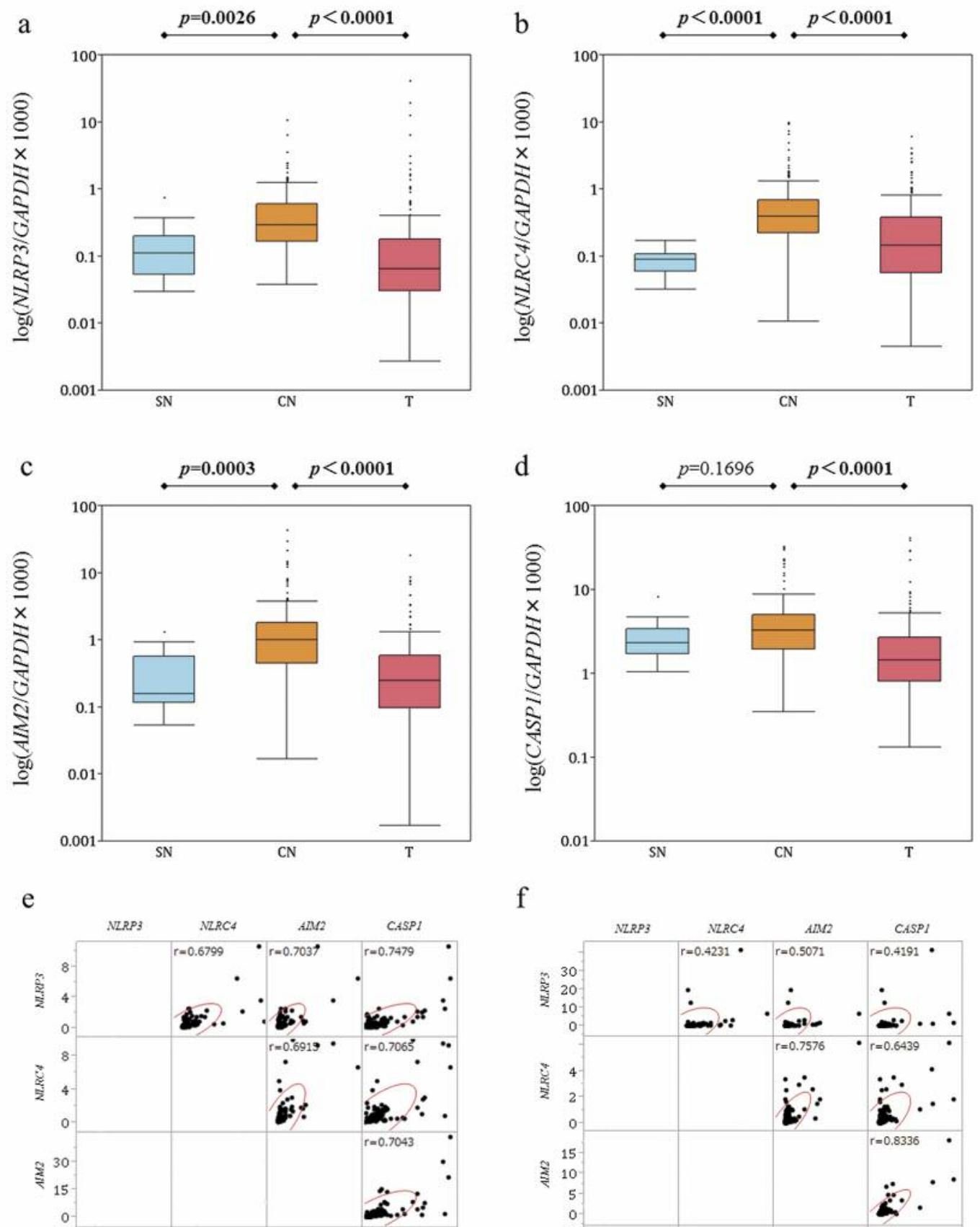

f

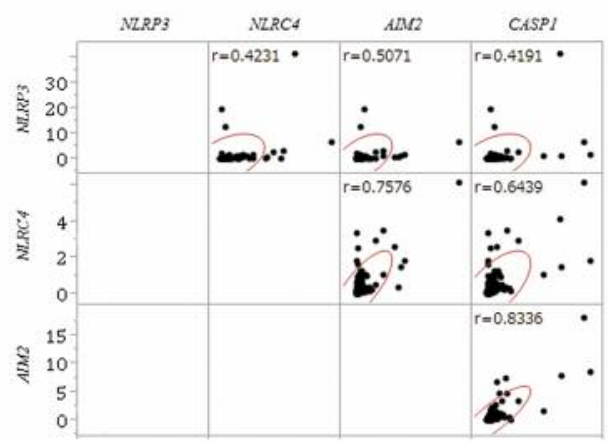

Figure 1. Box and whisker plots of expression levels of inflammasome components nod-like receptor family, pyrin domain containing 3 (NLRP3) (a), nod-like receptor family, CARD domain containing 4 (NLRC4) (b), absent in melanoma 2 (AIM2) (c) and caspase 1 (CASP1) (d) (as expression scorel glyceraldehyde-3-phosphate dehydrogenase $(G A P D H) \times 1,000)$. Expression levels of NLRP3, NLRC4 and AIM2 were significantly higher in corresponding normal tissue (CN) compared to hepatocellular carcinoma (HCC) tissue (T) (n 158) and super normal (SN) tissue ( $n=11)$. CASP1 expression in $C N(n=158)$ was significantly higher than that in $T(n=158)$. Correlations between expression of NLRP3, NLRC4, AIM2 and CASP1 in $C N(e)$ and $H C C(f)$. In $C N$, there was a strong positive correlation between the expression of these genes ( $1 \geq r \geq 0.7$ was considered strong correlation; $0.7>r \geq 0.4$ was considered moderate correlation). In HCC, the correlation between the expression of genes was moderate.

independent risk factors associated with survival. Correlation strengths were assessed using Spearman's rank correlation coefficient. All statistical analyses were performed using JMP Pro software version 11.0.0 (SAS International Inc., Cary, NC, USA). Acceptable statistical significance was set at $p<0.05$, as derived from two-tailed tests. 

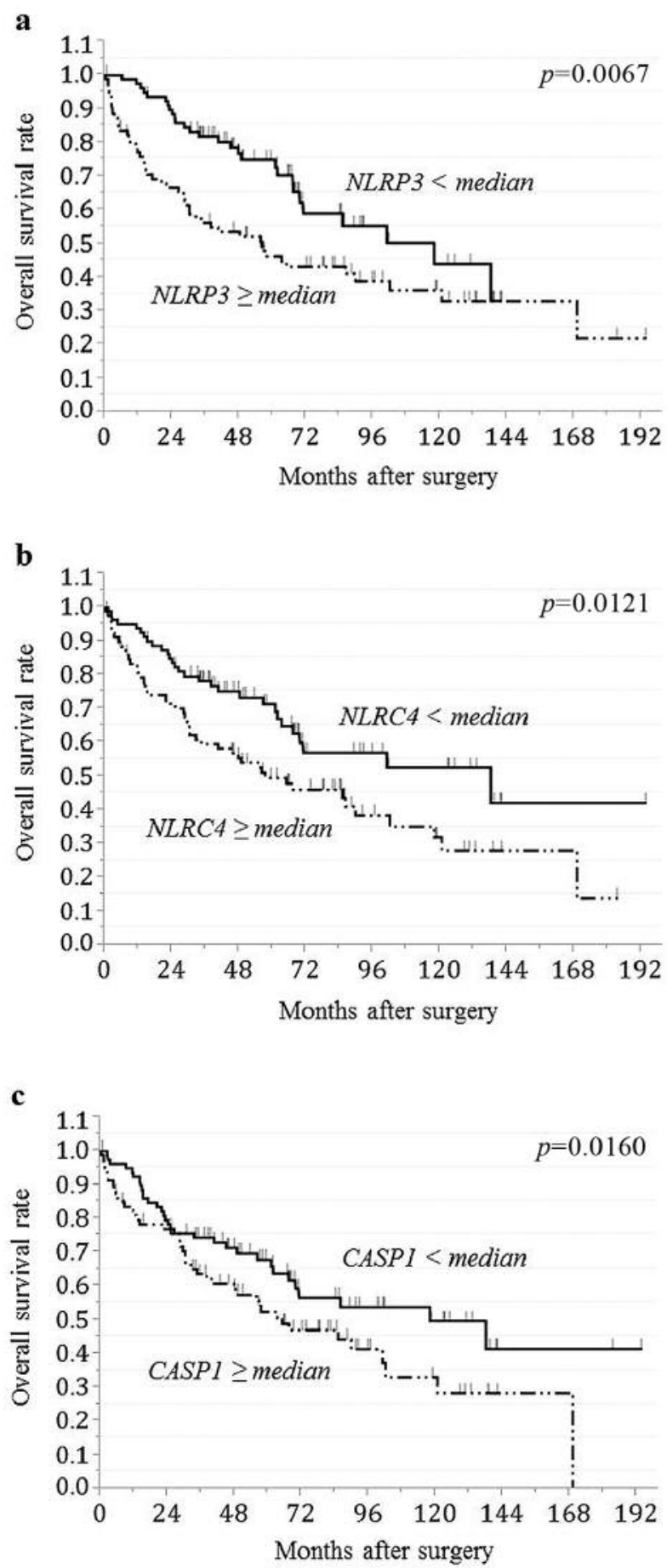

Figure 2. Overall survival rates of patients with hepatocellular carcinoma (HCC) stratified by inflammasome component mRNA expression levels in corresponding non-tumorous tissue. HCC cases $(n=158)$ were divided into two groups based on nod-like receptor family, pyrin domain containing 3 (NLRP3), nod-like receptor family, CARD domain containing 4 (NLRC4) and caspase 1 (CASP1) expression in HCC tissue $(T)$ and corresponding normal tissue $(C N)$ in each case $N L R P 3$ in $C N \geq$ median (a), NLRC4 in CN $\geq$ median (b), and CASP1 in $C N \geq$ median (c) was significantly correlated with worse overall survival (NLRP3: $p=0.0074$, NLRC4: $p=0.0121$, CASP1: $p=0.0160$ ).

\section{Results}

Real time quantitative RT-PCR analysis of $S N, C N$, and HCC tissues. When $158 \mathrm{HCC}$ cases were analyzed, the expression of overall inflammasome components that encoded the pattern recognition receptors NLRP3, NLRC4, and AIM2 was significantly higher in $\mathrm{CN}$ tissues compared to $\mathrm{HCC}$ tissues and SN tissues (Figure $1 \mathrm{a}-\mathrm{c}$ ). In addition, CASP1 expression was significantly higher in $\mathrm{CN}$ tissues compared to HCC tissues, but there was no significant difference in CASP1 expression between $\mathrm{CN}$ and $\mathrm{SN}$ tissues (Figure 1d). In $\mathrm{CN}$, there were strong positive correlations between the expressions of each gene, whereas the intergenic correlations in $\mathrm{HCC}$ were moderate (Figure 1e and f).

Correlations between expression of inflammasome components and clinicopathological characteristics of HCC. In order to evaluate the effect of inflammasome component expression on clinicopathological parameters, the median expression level of each gene in $\mathrm{CN}$ tissue was chosen as a cut-off value. The proportion of cases with high expression of NLRP3 in $\mathrm{CN}$ significantly differed in prothrombin time $(<70 / \geq 70 \%)$ $(p=0.0013)$ (Table II). The proportion of cases with high expression of NLRC4 in CN differed in tumor size $(\geq 2.0 /<2.0$ $\mathrm{cm})(p=0.0223)$ and growth type (infiltrative/expansive) $(p=0.0328)$ (data not shown). The proportion of cases with high expression of CASP1 in $\mathrm{CN}$ differed in virus type (HCV/other) $(p=0.0037)$ (data not shown).

Relationship between the expression of inflammasome components and HCC prognosis. As a result of real-time quantitative RT-PCR, 158 HCC cases were divided into two groups according to gene expression levels for inflammasome components for both HCC and $\mathrm{CN}$ tissues (<median and $\geq$ median) and the effect of expression on RFS and OS was evaluated. For HCC tissues, there was no significant difference in RFS or OS according to expression level. However, in $\mathrm{CN}$, high NLRP3, NLRC4, and CASPI expressions were associated with poorer OS, but not RFS (Figure 2) when compared with low expression levels. AIM2 expression levels were not associated with RFS or overall survival (data not shown). Furthermore, multivariate analysis confirmed significant correlations between OS and elevated serum alpha-fetoprotein level $(p=0.0353)$, serosal invasion $(p=0.0019)$, vascular invasion $(p=0.0276)$, and NLRP3 in CN $\geq$ median $(p=0.0302)$ (Table III).

\section{Discussion}

A major obstacle for HCC treatment is the high frequency of tumor recurrence even after curative resection and liver transplantation (20). Even in cases of small and welldifferentiated tumors, the recurrence rate remains high (21). 
Table III. Univariate and multivariate analysis of overall survival. A multivariate Cox proportional hazard model was used to investigate independent risk factors of overall survival. Significant p-values are shown in bold.

\begin{tabular}{|c|c|c|c|c|c|c|c|}
\hline \multirow[t]{2}{*}{ Clinicopathological factor } & & \multicolumn{3}{|c|}{ Univariate analysis } & \multicolumn{3}{|c|}{ Multivariate analysis } \\
\hline & & HR & $95 \% \mathrm{CI}$ & $p$-Value & HR & $95 \% \mathrm{CI}$ & $p$-Value \\
\hline Age & $\geq 65$ vs. $<65$ years & 1.55 & $0.98-2.48$ & 0.0585 & & & \\
\hline Gender & Men $v s$. women & 1.26 & $0.69-2.52$ & 0.4709 & & & \\
\hline Virus infection & HCV vs. other & 1.51 & $0.95-2.46$ & 0.0848 & & & \\
\hline Albumin & $<3.5 v s . \geq 3.5 \mathrm{~g} / \mathrm{dl}$ & 1.65 & $0.95-2.75$ & 0.0731 & & & \\
\hline PT & $<70 v s . \geq 70 \%$ & 1.75 & $0.91-3.12$ & 0.0914 & & & \\
\hline ICG R15 & $\geq 15$ vs. $<15 \%$ & 1.75 & $0.93-3.19$ & 0.0836 & & & \\
\hline Liver cirrhosis & Yes vs.no & 1.29 & $0.80-2.06$ & 0.2876 & & & \\
\hline Child-Pugh & B vs. A & 1.64 & $0.63-3.49$ & 0.2824 & & & \\
\hline Liver damage & $\mathrm{B}$ or $\mathrm{C} v s . \mathrm{A}$ & 2.07 & $1.16-3.51$ & 0.0149 & 2.33 & $1.20-4.26$ & 0.0130 \\
\hline Tumor number & Multiple $v s$. solitary & 1.68 & $0.99-2.75$ & 0.0534 & & & \\
\hline Tumor size & $\geq 2 v s .<2 \mathrm{~cm}$ & 2.03 & $0.95-5.24$ & 0.0681 & & & \\
\hline AFP & $\geq 20 \mathrm{vs} .<20 \mathrm{ng} / \mathrm{ml}$ & 2.07 & $1.30-3.30$ & 0.0022 & 1.86 & $1.05-3.28$ & 0.0312 \\
\hline Differentiation & Poor $v s$. well/moderate & 2.29 & $1.06-4.39$ & 0.0365 & 1.29 & $0.40-3.32$ & 0.6353 \\
\hline Growth form & Infiltrative $v s$. expansive & 1.58 & $0.86-2.72$ & 0.1334 & & & \\
\hline Formation of capsule & No vs. yes & 0.92 & $0.54-1.49$ & 0.7282 & & & \\
\hline Infiltration to capsule & Yes vs. no & 0.98 & $0.62-1.55$ & 0.9168 & & & \\
\hline Septal formation & Without vs. with & 1.06 & $0.64-1.71$ & 0.8221 & & & \\
\hline Serosal invasion & Yes vs. no & 2.52 & $1.48-4.17$ & 0.0009 & 2.67 & $1.51-4.62$ & 0.0010 \\
\hline Portal vein or hepatic vein invasion & With $v s$. without & 2.26 & $1.38-3.62$ & 0.0014 & 1.86 & $1.05-3.22$ & $\mathbf{0 . 0 3 3 1}$ \\
\hline Surgical margin & Positive vs. negative & 1.84 & $1.00-3.18$ & 0.0498 & 1.34 & $0.61-2.65$ & 0.4352 \\
\hline Japanese stage & $\mathrm{III} / \mathrm{IV} v s . \mathrm{I} / \mathrm{II}$ & 1.56 & $0.98-2.47$ & 0.0622 & & & \\
\hline$N L R P 3$ in $\mathrm{CN}$ & Median or higher $v s$. lower than median & 1.89 & $1.19-3.07$ & 0.0066 & 1.79 & $1.03-3.15$ & $\mathbf{0 . 0 3 7 3}$ \\
\hline
\end{tabular}

HR: Hazard ratio, CI: confidence interval, HCV: hepatitis C virus, PT: prothrombin time, ICG R15: indocyanine green 15-min retention rate, AFP: alpha fetoprotein, $N L R P 3$ : nod-like receptor family, pyrin domain-containing $3, \mathrm{CN}$ : corresponding normal tissue.

We previously reported that MO was more common than IM in HCC recurrence $(13,14)$. Accordingly, the detection of metachronous multicentric recurrent carcinoma at an earlier stage and the instigation of appropriate additional therapy may prolong survival in patients with MO (22). Furthermore, molecular elucidation of recurrence risks and prognosis using $\mathrm{CN}$ liver tissue could provide useful information alongside evaluation of the cancer tissue itself.

The present study revealed that inflammasome component genes $N L R P 3, N L R C 4$, and AIM2 were overexpressed in $\mathrm{CN}$ tissues when compared to HCC and $\mathrm{SN}$ tissues. These three proteins are pattern recognition receptors that react to various danger signals (23). NLPR3 has the greatest range of recognition and can sense different pathogens and dangerassociated molecular patterns (24), as well as toxic particles and UV radiation $(23,25)$. NLRC4 detects facultative intracellular pathogens such as Salmonella typhimurium, Shigella flexneri, Pseudomonas aeruginosa, Burkholderia thailandensis, and Legionella pneumophila (26). AIM2 activates caspase-1 when its DNA-binding HIN200 domain detects DNA from intracellular pathogens such as Francisella tularensis, cytomegalovirus, and vaccinia virus
(27). CASP1 acts an effector that leads to maturation of interleukin (IL)-1 $\beta$ and IL18 (28). In the present study, CASP1 expression in $\mathrm{CN}$ was significantly higher than that in HCC, but not that in SN.

The phenomena in the present study are interesting because while the surrounding non-tumorous tissue showed a highly inflammatory status related to inflammasomes, the HCC tumor tissue itself did not. Furthermore, high expression levels of three genes of the inflammasome components in $\mathrm{CN}$ were associated with significantly worse OS. Moreover, higher expression of inflammasome component genes was related, not only to background liver pathological status, such as decreased prothrombin time and viral infection type, but also to tumor factors including tumor size and growth type. According to the present study, high gene expression of inflammasome components in $\mathrm{CN}$ are not simply caused by background hepatitis status and this might be the indirect result of malignancy in the adjacent HCC tissue.

In the present study, high expression of $N L R P 3$ in $\mathrm{CN}$ was an independent prognostic factor related to poorer OS. Few studies have suggested a relationship between NLRP3 and 
neoplasms. Recently, Fan et al. demonstrated that luteoloside exerted an inhibitory effect on proliferation, invasion, and metastasis of HCC cells via NLRP3 inflammasome inhibition (29). In addition, Ungerbäck et al. proposed that NLRP3 (Q705K) polymorphisms were associated with poor survival in patients with advanced colorectal cancer and they suggested the utility of $N L R P 3$ polymorphisms as prognostic markers (30). To our knowledge, there have been no studies showing the relationships between inflammasome component expressions in background non-tumorous tissues and HCC prognosis.

In the present study, the expression of genes encoding pattern recognition receptors were significantly elevated in $\mathrm{CN}$ tissues of $\mathrm{HCC}$, suggesting that high expression of these genes in non-tumorous liver tissues might be useful as predictive markers of $\mathrm{HCC}$. In addition, expression of these markers in $\mathrm{CN}$, rather than $\mathrm{HCC}$ tissue, could be useful as post-surgical prognosticators allowing for better patient selection for more intense follow-up programs, such as frequent examination with ultrasonography or computed tomography and adjuvant therapy. However, the present study had limitations such as being a single-institute retrospective study. In addition, how inflammasomes might mechanistically affect carcinogenesis or tumor malignancy has not been determined and such knowledge could provide a great opportunity for novel approaches to prediction, prevention, and exploitation of molecular-targeted therapy for HCC.

In conclusion, our findings suggest that high expression of inflammasome components in background non-tumorous liver tissue of HCC might be good prognostic biomarkers for curatively resected HCC. Thus, in combination with other tumor prognostic factors, these background markers might lead to a more accurate prediction of HCC prognosis.

\section{Conflicts of Interest}

All the Authors declare that they have no coflict of interest.

\section{Ethical Approval}

All procedures performed in studies involving human participants were in accordance with the ethical standards of the Institutional Review Board in Nagoya University Graduate School of Medicine (Nagoya, Japan) and with the 1964 Helsinki declaration and its later amendments.

Informed consent was obtained from all individual participants included in the study.

\section{Acknowledgements}

Funding: This study was funded by Japan Society for the Promotion of Science (JSPS) KAKENHI Grant-in-Aid for Scientific Research (C) (26461908, Hiroyuki Sugimoto).

\section{References}

1 Alnemri ES: Sensing cytoplasmic danger signals by the inflammasome. J Clin Immunol 30: 512-519, 2010.

2 Chen MS, Li JQ, Zheng Y, Guo RP, Liang HH, Zhang YQ, Lin $\mathrm{XJ}$ and Lau WY: A prospective randomized trial comparing percutaneous local ablative therapy and partial hepatectomy for small hepatocellular carcinoma. Ann Surg 243: 321-328, 2006.

3 Chen PJ, Chen DS, Lai MY, Chang MH, Huang GT, Yang PM, Sheu JC, Lee SC, Hsu HC and Sung JL: Clonal origin of recurrent hepatocellular carcinomas. Gastroenterology 96: 527529, 1989.

4 Cucchetti A, Piscaglia F, Caturelli E, Benvegnu L, Vivarelli M, Ercolani G, Cescon M, Ravaioli M, Grazi GL, Bolondi L and Pinna AD: Comparison of recurrence of hepatocellular carcinoma after resection in patients with cirrhosis to its occurrence in a surveilled cirrhotic population. Ann Surg Oncol 16: 413-422, 2009.

5 Fan SH, Wang YY, Lu J, Zheng YL, Wu DM, Li MQ, Hu B, Zhang ZF, Cheng W and Shan Q: Luteoloside suppresses proliferation and metastasis of hepatocellular carcinoma cells by inhibition of NLRP3 inflammasome. PloS One 9: e89961, 2014.

6 Hanahan D and Weinberg RA: Hallmarks of Cancer: The Next Generation. Cell 144: 646-674, 2011.

7 Imamura H, Matsuyama Y, Tanaka E, Ohkubo T, Hasegawa K, Miyagawa S, Sugawara Y, Minagawa M, Takayama T, Kawasaki $\mathrm{S}$ and Makuuchi M: Risk factors contributing to early and late phase intrahepatic recurrence of hepatocellular carcinoma after hepatectomy. J Hepatol 38: 200-207, 2003.

8 Kobayashi A, Kawasaki S, Miyagawa S, Miwa S, Noike T, Takagi S, Iijima S and Miyagawa Y: Results of 404 hepatic resections including 80 repeat hepatectomies for hepatocellular carcinoma. Hepatogastroenterology 53: 736-741, 2006.

9 Kumada T, Nakano S, Takeda I, Sugiyama K, Osada T, Kiriyama S, Sone Y, Toyoda H, Shimada S, Takahashi M and Sassa T: Patterns of recurrence after initial treatment in patients with small hepatocellular carcinoma. Hepatology 25: 87-92, 1997.

10 Lamkanfi $M$ and Dixit VM: Mechanisms and functions of inflammasomes. Cell 157: 1013-1022, 2014.

11 Lamkanfi $\mathrm{M}$ and Dixit VM: Modulation of inflammasome pathways by bacterial and viral pathogens. J Immunol 187: $597-$ 602, 2011.

12 Martinon F, Burns $\mathrm{K}$ and Tschopp J: The inflammasome: a molecular platform triggering activation of inflammatory caspases and processing of proIL-beta. Mol Cell 10: 417-426, 2002.

13 Martinon F and Tschopp J: Inflammatory caspases and inflammasomes: master switches of inflammation. Cell Death Differ 14: 10-22, 2007.

14 Matsuda M, Fujii H, Kono H and Matsumoto Y: Surgical treatment of recurrent hepatocellular carcinoma based on the mode of recurrence: repeat hepatic resection or ablation are good choices for patients with recurrent multicentric cancer. J Hepatobiliary Pancreat Surg 8: 353-359, 2001.

15 Menu P and Vince JE: The NLRP3 inflammasome in health and disease: the good, the bad and the ugly. Clin Exp Immunol 166: $1-15,2011$ 
16 Morimoto O, Nagano H, Sakon M, Fujiwara Y, Yamada T, Nakagawa H, Miyamoto A, Kondo M, Arai I, Yamamoto T, Ota H, Dono K, Umeshita K, Nakamori S, Sasaki Y, Ishikawa O, Imaoka $\mathrm{S}$ and Monden $\mathrm{M}$ : Diagnosis of intrahepatic metastasis and multicentric carcinogenesis by microsatellite loss of heterozygosity in patients with multiple and recurrent hepatocellular carcinomas. J Hepatol 39: 215-221, 2003.

17 Nakata T, Seki N, Miwa S, Kobayashi A, Soeda J, Nimura Y, Kawasaki S and Miyagawa S: Identification of genes associated with multiple nodules in hepatocellular carcinoma using cDNA microarray: Multicentric occurrence or intrahepatic metastasis? Hepatogastroenterology 55: 865-872, 2008.

18 Nomoto S, Hishida M, Inokawa Y, Takano N, Kanda M, Nishikawa Y, Fujii T, Koike M, Sugimoto H and Kodera Y: Expression analysis of THOP1 in background liver, a prognostic predictive factor in hepatocellular carcinoma, extracted by multiarray analysis. Ann Surg Oncol 21(Suppl 3): S443-450, 2014.

19 Nomoto S, Kinoshita T, Kato K, Otani S, Kasuya H, Takeda S, Kanazumi N, Sugimoto H and Nakao A: Hypermethylation of multiple genes as clonal markers in multicentric hepatocellular carcinoma. Br J Cancer 97: 1260-1265, 2007.

20 Nomoto S, Yamashita K, Koshikawa K, Nakao A and Sidransky D: Mitochondrial D-loop mutations as clonal markers in multicentric hepatocellular carcinoma and plasma. Clin Cancer Res 8: 481-487, 2002.

21 Parkin DM, Bray F, Ferlay J and Pisani P: Global cancer statistics, 2002. CA Cancer J Clin 55: 74-108, 2005.

22 Petrilli V, Dostert C, Muruve DA and Tschopp J: The inflammasome: a danger sensing complex triggering innate immunity. Curr Opin Immunol 19: 615-622, 2007.

23 Portolani N, Coniglio A, Ghidoni S, Giovanelli M, Benetti A, Tiberio GA and Giulini SM: Early and late recurrence after liver resection for hepatocellular carcinoma: prognostic and therapeutic implications. Ann Surg 243: 229-235, 2006.
24 Rahbari NN, Mehrabi A, Mollberg NM, Muller SA, Koch M, Buchler MW and Weitz J: Hepatocellular carcinoma: current management and perspectives for the future. Ann Surg 253: 453$469,2011$.

25 Schroder K and Tschopp J: The Inflammasomes. Cell 140: 821$832,2010$.

26 Takenaka K, Adachi E, Nishizaki T, Hiroshige K, Ikeda T, Tsuneyoshi M and Sugimachi K: Possible multicentric occurrence of hepatocellular carcinoma: a clinicopathological study. Hepatology 19: 889-894, 1994

27 Taura K, Ikai I, Hatano E, Fujii H, Uyama N and Shimahara Y: Implication of frequent local ablation therapy for intrahepatic recurrence in prolonged survival of patients with hepatocellular carcinoma undergoing hepatic resection: an analysis of 610 patients over 16 years old. Ann Surg 244: 265-273, 2006.

28 Ungerback J, Belenki D, Jawad ul-Hassan A, Fredrikson M, Fransen K, Elander N, Verma D and Soderkvist P: Genetic variation and alterations of genes involved in NFkappaB/ TNFAIP3 and NLRP3 inflammasome signaling affect susceptibility and outcome of colorectal cancer. Carcinogenesis 33: 2126-2134, 2012.

29 Wang Z, Zhang G, Wu J and Jia M: Adjuvant therapy for hepatocellular carcinoma: current situation and prospect. Drug Discov Ther 7: 137-143, 2013.

30 Zitvogel L, Kepp O, Galluzzi L and Kroemer G: Inflammasomes in carcinogenesis and anticancer immune responses. Nat Immunol 13: 343-351, 2012. 